\title{
ANÁLISE DE TEXTOS E ESTILO - POR UMA LEITURA DESACOSTUMADA NA TEORIA E NA PRÁTICA
}

\author{
Fabio André Coelho (UERJ) \\ Lúcia Deborah de Araújo (UERJ/CPII) \\ Palavra poética tem que chegar ao grau de brinquedo \\ para ser séria. \\ Manoel de Barros
}

Resumo: A Estilística e seu lugar na abordagem da leitura e da interpretação de texto no espaço da escola básica - esse é o objeto deste artigo. Entendemos que o trabalho, a partir do estilo, permite realizar leituras mais amplas, abrindo espaço para que o leitor iniciante adentre o universo significativo construído pelo autor e, com isso, estabeleça uma relação produtiva com o texto em geral e, mais especificamente, com o texto literário, muitas vezes tido como opaco para o leitor escolar. Neste artigo, realizamos um apanhado conceitual das teorias no campo da Estilística, com breves considerações a respeito de cada referencial, com vistas a produzir um quadro representativo das abordagens possíveis. Em seguida, apresentamos um relato de sequência didática desenvolvida em sala de aula do ensino médio, no Colégio Pedro II. Colocada em discussão o projeto de simplificação de clássicos da literatura, apoiado pelo Ministério da Educação, desenvolveram-se atividades em que foi possível demonstrar a perspectiva que os alunos têm sobre a questão do estilo, bem como se pôde averiguar como lidam com o texto e seus recursos expressivos, alimentando sua leitura e ampliando suas possibilidades de interpretação. Para tanto, foram usados textos de João Ubaldo Ribeiro, Machado de Assis e Mia Couto. Por fim, tomamos posição sobre o lugar da Estilística no ensino básico e discutimos o papel do professor numa abordagem que pretenda explorar o estilo do texto como plataforma para que o estudante desenvolva um olhar mais preparado para a literatura, encontrando prazer na leitura. Palavras-chave: Texto; Estilo; Ensino.

Resumen: La Estilística y su lugar en el abordaje de la lectura y de la interpretación de texto en el espacio de la escuela básica - ese es el 
objeto de este artículo. Comprendemos que el trabajo a partir del estilo permite realizar lecturas más amplias, abriendo espacio para que el lector iniciante ingrese en el universo significativo construido por el autor $y$, con eso, establezca una relación productiva con el texto en general y, más específicamente, con el texto literario, muchas veces clasificado como opaco para el lector escolar. En este trabajo, realizamos un resumen conceptual de las teorías en el campo de la Estilística, con breves consideraciones acerca de cada referencial, con vistas a producir un cuadro representativo de los abordajes posibles. Enseguida, presentamos un relato de secuencia didáctica desarrollada en aula de la enseñanza media, en el Colégio Pedro II. Puesto en discusión el proyecto de simplificación de clásicos de la literatura, apoyado por el Ministerio de la Educación, algunas actividades fueron desarrolladas en que fue posible demostrar la perspectiva que los alumnos tienen de la cuestión del estilo, así como se pudo comprobar como lidian con el texto y sus recursos expresivos, alimentando su lectura y ampliando sus posibilidades de interpretación. Para eso, textos de João Ubaldo Ribeiro, Machado de Assis e Mia Couto fueron usados. Al fin y al cabo, tomamos posición sobre el lugar de la Estilística en la enseñanza básica y discutimos el papel del profesor en un abordaje que busque explorar el estilo del texto como plataforma para que el estudiante desarrolle una mirada más preparada para la literatura, hallando placer en la lectura. Palabras clave: Texto; Estilo; Enseñanza.

\section{POR UMA LEITURA DESACOSTUMADA - NA TEORIA}

A relação entre texto e estilo sempre mereceu um cuidado especial nos estudos da Língua, com destaque para o fenômeno da expressividade da linguagem, do uso elegante e estilístico das palavras, tendo em vista as (im)precisões e o subjetivismo responsável por caracterizar os elementos afetivos dos discursos, inclusive, o literário.

A Estilística revela-se como ciência, em 1902, com Charles Bally, iniciando os estudos de uma Estilística da língua ou da 
expressão linguística, que se detém na descrição do aparato expressivo da língua, em sua totalidade, em contraponto a um estudo dos estilos individuais, provocando, assim, um afastamento da literatura (REI, 2002). A partir da Estilística idealista de Leo Spitzer, seguida, então, por Dámaso Alonso e Amado Alonso, distintamente dos princípios de Bally, Vossler e Auerbach pela modernidade, que os estudos da expressão literária começaram a avançar, iniciando-se uma reformulação crítica no processo literário. A antiga retórica abre espaço para a Estilística, em cujos preceitos já não se exige o uso de uma "bela língua", fria, pelas regras gramaticais. A língua, uma expressão do homem, evolui com ele, com os costumes, os ideais e os usos que exprime (GUIRAUD, 1970). Esse novo espaço provoca a alteração conceitual de linguagem e de estilo. No percurso, há duas grandes correntes da Estilística denominadas "descritiva" e "idealista", diferentes no tratamento do objeto de estudo: o texto.

Do ponto de vista conceitual, os estilólogos apresentam divergências entre as várias teorias. Com a tradição, apreendemos o sentido da Estilística como ciência e como a arte de bem escrever, falar e dizer, com vistas à língua padrão. Percebemos, ao longo da história linguística, variadas representações da expressão Estilística e nos deparamos com 
uma nova ciência, a partir de Saussure e discípulos. Novas percepções e considerações convergem para a ampliação das análises da língua.

Os estudos de Charles Bally se voltam para aspectos afetivos da língua falada, daquela que serve aos usuários, caracterizada pela sua espontaneidade, mas que atende às regras da gramaticalização, com um sistema expressivo descrito e examinado pela Estilística. O autor postula a linguagem sob duas faces: a intelectiva ou lógica e a afetiva. Analisa os efeitos da afetividade em seu uso e de que maneira a impessoalidade linguística se transforma na produção da fala. Pioneiro na distinção entre o conteúdo linguístico e o conteúdo estilístico, o autor preocupou-se em demonstrar as variadas possibilidades de se perceberem as diferentes maneiras da expressão verbal. Martins (2000) aponta a classificação dos efeitos significativos por meio dos quais o homem manifesta seus sentimentos e mantém suas relações com o outro, como: naturais (manifestações de prazer e desprazer, de admiração, e desaprovação, processos de intensificação de ideias e evocativos, instituídos em determinados grupos sociais ou dadas épocas e revelados na língua familiar, gíria, linguagem do trabalho, literária, entre outras). De acordo com a concepção saussuriana, 
Bally dedica-se aos estudos da langue, importando-se com o sistema expressivo da língua, e afastando-se da perspectiva de estudo da parole, ou seja, do uso individual da língua. Para ele:

A Estilística estuda os fatos da expressão da linguagem, organizada do ponto de vista do seu conteúdo afetivo, isto é, a expressão dos fatos da sensibilidade pela linguagem e a ação dos fatos da linguagem sobre a sensibilidade. (Apud MARTINS, 2000, p.4)

É com tal pensamento que o autor estabelece ideias sobre a Estilística da língua ou da expressão linguística, observando as características expressivas do aparato linguístico, e opõe-se aos estudos dos estilos individuais, com que se preocupava a literatura.

Com Marouzeau, há uma Estilística discursiva, que estabelece o lugar da língua a serviço de seus usuários e o respeito às necessidades expressivas de cada um, na confirmação das escolhas e na produção do estilo. Juntamente com Cressot, inclina-se para a Estilística literária, por considerar a língua literária, com seus recursos expressivos, o campo de estudo de excelência da ciência.

Na sequência dos princípios de Bally, aparecem, em destaque, Manuel Rodrigues Lapa e Mattoso Câmara Jr. 
Por meio das obras consagradas dos autores, verificamos a redimensão dos estudos estilísticos e a defesa pelo reconhecimento da ciência estilística.

Na elaboração da obra de Lapa, há a despreocupação na formulação dos conceitos de estilo e Estilística. Em contrapartida, imprime a dedicação do autor em dar a característica aplicativa aos assuntos tratados na obra. Destaca os valores expressivos das classes de palavras, do léxico e das combinações sintáticas, na tentativa de apresentar uma língua "sentida" pelo falante. Posiciona-se:

Vemos pois que, em volta de cada palavra ou, para melhor dizer, de certas palavras, se estabelece uma atmosfera fantasiosa e sentimental que constitui o seu valor expressivo. Há, evidentemente, palavras mais evocadoras do que outras. O bom escritor saberá aproveitá-las, para suscitar mais vivas e variadas imagens. Mas uma coisa é necessária a quem deseja conhecer a fundo a sua língua e utilizá-la para fins artísticos: pensar e sentir as palavras como se elas fossem feitas de novo, e evocar o objeto a que se referem com a maior frescura e vivacidade possível. (LAPA, 1998, p.4)

As possibilidades expressivas na obra de Câmara Jr. são balizadas na concepção estilística das três funções da linguagem de Karl Bühler: representação (linguagem intelectiva), expressão (expressão ou manifestação psíquica) 
e apelo (linguagem afetiva de Bally). A sua depreensão, em relação à langue, concentra-se em apresentar a Estilística como estudo da língua enquanto sistema de expressividade. Destacam-se, entre outros aspectos, o caráter da língua como representação mental da realidade e as utilizações, por parte dos falantes, e a finalidade de expressar a subjetividade dos usuários. Além disso, na perspectiva da visão saussuriana, atentemos ao que o linguista esclarece:

A língua, no conceito saussuriano, se deduz apenas da função representativa, pois compreende a estrutura, o esquema, o padrão ou a pauta que rege, em termos linguísticos, a nossa representação do mundo exterior e interior. Resulta de um trabalho de intuição infrarracional, mas de caráter intelectivo, que justamente a gramática se propõe a trazer para o plano da consciência, pondo-lhe em evidência os sistemas de sons, de formas, de significações e de ordenação de elementos, ou sejam - o fônico, o mórfico, o semântico e o sintático. (1978, p.10)

Leo Spitzer inaugura a chamada Estilística literária (idealista) com base na filosofia idealista de Croce e Vossler. A percepção dos estudos filológicos consiste na adoção da hermenêutica dos textos literários, na localização dos traços estilísticos marcantes e na análise psicológica desses traços, 
a fim de atestar sua relevância e pertinência, conforme Monteiro (2005). A análise proposta por Spitzer se concentra nos desvios da linguagem formal influenciados pelo estado psíquico de seus usuários. O escritor revela, por meio da escrita e do uso da língua, as expressões e as impressões do mundo interior. É mister a orientação seguida pelo estilólogo na proposta de análise linguística direcionada aos estudos da parole e ao estilo formador da personalidade discursiva.

Na filiação do pensamento spitzeriano, seguem outros estudiosos, como Dámaso Alonso e Amado Alonso. O primeiro é mais representativo, pela grandeza de trabalhos férteis acerca da obra artística. Para ele, o objeto da Estilística caracteriza-se pela sua amplitude e expressividade, abrangendo "o imaginário, o afetivo e o conceitual" (Apud MARTINS, 2000, p.8). Em sua concepção, apesar de a obra literária compreender segredos e requerer mecanismos intuitivos para as análises literárias, torna-se viável o estudo científico dos elementos significativos inseridos na linguagem. Há a negativa de qualquer racionalidade para o método estilístico, em defesa da ideia da capacidade intuitiva para o acesso do universo literário.

Aproximam-se Dámaso Alonso e Leo Spitzer, no tocante à visão psicologista e à abordagem intuitiva da língua 
e distanciam-se, ao estabelecerem o foco estilístico de suas análises textuais. Para Martins, "Enquanto Spitzer se mostrava mais preocupado com a manifestação do autor na obra, Dámaso Alonso se sente mais espicaçado pelo mistério da criação poética, pela pergunta: 0 que é o poema? 0 que é a obra literária?" (2000, p.10).

Amado Alonso, com sua argúcia, se insere na fusão dos postulados de Bally e Spitzer. O objeto da Estilística consiste no sistema expressivo do discurso literário, na estrutura e na potencialidade sugestiva das palavras. Constatamos, por um lado, a eficácia da técnica; por outro, a necessidade da sensibilidade para a fruição artística. Assim, os caminhos seguidos pela ciência estilística se associam aos aspectos da construção do texto e ao prazer da dimensão estética da palavra. Segundo Martins: "A Bally se prende a sua concepção dos elementos afetivos, ativos, imaginativos e valorativos da linguagem. A Spitzer a sua compreensão do estilo como revelação do homem" (2000, p.10).

Na perspectiva da fundamentação de novas teorias, vários estudiosos investigam, tentam estabelecer parâmetros para a análise linguístico-expressiva dos textos. Os fatos estilísticos são observados mediante as manifestações anímicas da estrutura da língua. A partir das concepções de 
Martins (2000) e Monteiro (2005), enumeramos as teorias e as definições de cada corrente da trajetória da Estilística, para compreensão mais didática e normativa:

\begin{tabular}{|c|c|c|}
\hline CORRENTES & TEÓRICOS & DEFINIÇÕES \\
\hline Descritiva & $\begin{array}{l}\text { Bally } \\
\text { Marouzeau } \\
\text { Cressot }\end{array}$ & $\begin{array}{l}\text { De acordo com sua percepção, } \\
\text { caberia à Estilística investigar "a } \\
\text { expressão dos fatos da sensibilidade } \\
\text { pela linguagem e a ação dos fatos } \\
\text { de linguagem sobre a sensibilidade" } \\
\text { (BALLY, 1951, p.16 et passim). E tal } \\
\text { estudo incidiria basicamente em } \\
\text { três vastos campos de aplicação: a) } \\
\text { a linguagem em geral (os universais } \\
\text { estilísticos); b) uma dada língua (a } \\
\text { Estilística da langue); c) o sistema } \\
\text { expressivo de um indivíduo isolado } \\
\text { (a Estilística da parole). (MONTEIRO, } \\
2005, \text { p.16) }\end{array}$ \\
\hline Idealista & $\begin{array}{l}\text { Leo Spitzer } \\
\text { Dámaso Alonso } \\
\text { Amado Alonso } \\
\text { Devoto } \\
\text { José Luis Martín } \\
\text { Helmut Hatzfeld }\end{array}$ & $\begin{array}{l}\text { A Estilística de Spitzer parte da } \\
\text { reflexão, de cunho psicologista, } \\
\text { sobre os desvios da linguagem em } \\
\text { relação ao uso comum; uma emoção, } \\
\text { uma alteração do estado psíquico } \\
\text { normal provoca um afastamento do } \\
\text { uso linguístico normal; um desvio da } \\
\text { linguagem usual, é, pois, indício de } \\
\text { um estado de espírito não habitual. } \\
\text { O estilo do escritor - a sua maneira } \\
\text { individual de expressar-se - reflete } \\
\text { o seu mundo interior, a sua vivência. } \\
\text { (MARTINS, 2000, p.7) }\end{array}$ \\
\hline
\end{tabular}




\begin{tabular}{|c|c|c|}
\hline Estrutural & $\begin{array}{l}\text { Rifaterre } \\
\text { Samuel Levin } \\
\text { Dolezel }\end{array}$ & $\begin{array}{l}\text { Rifaterre considera a Estilística } \\
\text { estudo exclusivo da mensagem, } \\
\text { negando a pertinência estilística do } \\
\text { sistema (o que se pode considerar uma } \\
\text { posição radical contestável). O estilo é } \\
\text { fato resultante da forma da mensagem } \\
\text { e repousa sobre uma dupla série } \\
\text { de procedimentos: uns decorrentes } \\
\text { de uma convergência (paralelismo, } \\
\text { colocação de elementos linguísticos } \\
\text { equivalentes - fônicos e semânticos } \\
\text { - em posições equivalentes), e outros } \\
\text { decorrentes dum contraste de signos. } \\
\text { (...) Ponto importante da teoria de } \\
\text { Rifaterre é a ênfase dada ao leitor: o } \\
\text { estudo do estilo só pode ser definido } \\
\text { em função do leitor, sendo destituída de } \\
\text { pertinência estilística toda referência ao } \\
\text { autor. (MARTINS, 2000, p.15) }\end{array}$ \\
\hline Gerativa & Ohmann & $\begin{array}{l}\text { Sejacomofor, as análises estilísticas } \\
\text { que se fundamentam na teoria } \\
\text { gerativo-transformacional optam por } \\
\text { um enfoque desviacionista. O ponto } \\
\text { de partida é a constatação de que, } \\
\text { na literatura em geral e na poesia em } \\
\text { particular, é muito comum a ocorrência } \\
\text { de frases tidas como agramaticais ou } \\
\text { inaceitáveis para o falante. A explicação } \\
\text { deste fenômeno subjaz no fato de que } \\
\text { a linguagem literária viola o sistema } \\
\text { de regras sintáticas e semânticas que } \\
\text { constituem a gramática padrão. E, } \\
\text { assim, o objeto da Estilística gerativa } \\
\text { não seria outro senão o de definir as } \\
\text { regras de uma gramática da literatura. } \\
\text { (MONTEIRO, 2005, p.28) }\end{array}$ \\
\hline
\end{tabular}




\begin{tabular}{|c|c|c|}
\hline Retórica & Dubois & $\begin{array}{l}\text { O esquema proposto por Dubois } \\
\text { parte da distinção, concebida } \\
\text { por Hjelmslev, entre os planos da } \\
\text { expressão e do conteúdo. No plano da } \\
\text { expressão, distingue os metaplasmos } \\
\text { das metataxes; no do conteúdo, os } \\
\text { metassememas dos metalogismos. (...) } \\
\text { Mas, seja como for, a Retórica passa a } \\
\text { ser redefinida como um conjunto de } \\
\text { desvios (metáboles) que modificam o } \\
\text { nível de redundância da língua, o que } \\
\text { se torna perceptível em virtude de uma } \\
\text { marca. E a análise de tais alterações, } \\
\text { que incidem em qualquer aspecto } \\
\text { da língua, constitui um campo fértil } \\
\text { para a descoberta dos fatos de estilo. } \\
\text { (MonTEIRO, 2005, p.29) }\end{array}$ \\
\hline Poética & $\begin{array}{l}\text { Jakobson } \\
\text { Cohen } \\
\text { Delas } \\
\text { Filliolet }\end{array}$ & $\begin{array}{l}\text { Para Jakobson (1963, p.219), “o } \\
\text { estudo linguístico da função poética } \\
\text { deve ultrapassar os limites da poesia } \\
\text { e, por outro lado, a análise linguística } \\
\text { da poesia não pode circunscrever-se } \\
\text { à função poética” (Apud MONTEIRO, } \\
\text { 2005, 31). Não é difícil perceber que } \\
\text { os recursos existentes nas mensagens } \\
\text { literárias aparecem também na } \\
\text { linguagem da publicidade ou em } \\
\text { qualquer manifestação linguística } \\
\text { em que, de uma forma ou de outra, } \\
\text { o usuário exerça um domínio sobre } \\
\text { a língua quando a emprega para fins } \\
\text { expressivos. (MONTEIRO, 2005, p.31) }\end{array}$ \\
\hline
\end{tabular}




\begin{tabular}{|c|c|c|}
\hline Semiótica & Blanchard & $\begin{array}{l}\text { A verdade é que, com a constatação } \\
\text { de que os métodos linguísticos devem } \\
\text { ultrapassar o domínio da frase para dar } \\
\text { conta dos mecanismos estruturadores do } \\
\text { discurso, surgiu também uma tendência } \\
\text { para ampliar os limites da Poética, } \\
\text { passando a obra literária a ser vista } \\
\text { dentro de uma configuração muito mais } \\
\text { abrangente. A Estilística reformulada } \\
\text { semioticamente é concebida como uma } \\
\text { disciplina cujo escopo englobaria todos } \\
\text { os temas relacionados às linguagens } \\
\text { enquanto sistema de signos. (MONTEIRO, } \\
\text { 2005, p.34) }\end{array}$ \\
\hline Estatística & $\begin{array}{l}\text { Guiraud } \\
\text { Monteiro } \\
\text { Roche }\end{array}$ & $\begin{array}{l}\text { Para Guiraud (1959), é pela } \\
\text { frequência das palavras ou de qualquer } \\
\text { elemento que o escritor age sobre o } \\
\text { leitor, sendo o estilo resultante de um } \\
\text { desvio que se define quantitativamente } \\
\text { em relação a uma norma. Surge daí } \\
\text { uma hipótese bastante sedutora que } \\
\text { se liga à questão das palavras-tema e } \\
\text { das palavras-chave. As primeiras são } \\
\text { as mais empregadas num determinado } \\
\text { corpus; as outras são aquelas cuja } \\
\text { ocorrência se caracteriza como um } \\
\text { desvio. (...) O uso mais ou menos } \\
\text { generalizado de uma expressão é que } \\
\text { cria e condiciona o seu valor estilístico. } \\
\text { (MONTEIRO, 2005, p.37) }\end{array}$ \\
\hline
\end{tabular}

Notam-se os limites frágeis e flutuantes entre as áreas da Estilística e a necessidade do esmero com os axiomas do sistema estilístico. Em contrapartida, observamos o 
reconhecimento dos estudiosos da área, em função dos levantamentos sobre a produção e a recepção do estilo, e a situação social de uso, por validar a capacidade de veiculação dos significados determinantes na concepção estilística.

Baseada na análise semiótica de estilos, Discini (2009) trata estilo e norma com a verificação das relações sintáticas e semânticas presentes no plano do conteúdo (metaplasmos/ nível morfológico, metataxes/nível da sintaxe) e no plano da expressão (metassememas/nível da semântica, metalogismos/ nível lógico). No trabalho, a determinação de significados dos textos colaborará para a representação do estilo. No percurso gradativo, a reconstrução dos sentidos dos textos aumentará a compreensão da produção discursiva e do estilo. Para a autora, a norma se forma por meio de variadas circunstâncias geradoras de sentidos. Com base nos estudos de Hjelmslev (1943), reforça a substituição da dicotomia saussuriana língua/ fala, pela relação esquema/norma/uso/ato, se baseando na perspectiva de aproximação da língua com seu ato individual, por consequência, com o estilo. A norma constituir-se-ia em tentativa de compilação da descrição do uso. Por fim, considera o esquema e o uso, em substituição à língua e à fala.

O interesse de Possenti (2001) concentra-se na consideração do estilo como fato de língua e na descrição 
da tarefa da Estilística: caracterização da personalidade, isolamento dos traços do sistema linguístico (independentes da coletividade), contribuição para uma espécie de língua individual e concatenação e interpretação dos dados expressivos. A apresentação do estilo como desvio da norma direciona para a individualização da personalidade. A abordagem da questão estilística, na visão dos estruturalistas e gerativistas, apresenta problema na concepção de língua e de gramática. Em Saussure, a língua é concebida com uniformidade e a competência gramatical gerativa pode-se expressar pelo conhecimento de um falante-ouvinte apurado. Os traços estilísticos se revelam na variação linguística, no fato de o sujeito explorar os recursos expressivos, utilizandose da diversidade de códigos. Estabelecer os papéis de uso da língua, a partir do esquema estrutural e situação social do usuário e perceber a diversidade na apresentação discursiva do falante. A distinção de um falante para outro se confirma por meio das diferenças entre a ordem estrutural das frases e a utilização da linguagem. Temos, assim, a língua exteriorizada na potencialidade expressiva e plural.

\section{POR UMA LEITURA DESACOSTUMADA - NA PRÁTICA}

Sempre que discutimos o lugar da abordagem estilística, surgem questões e reflexões acerca da leitura, já que o 
estabelecimento de uma conexão entre leitor e texto passa, necessariamente, pelas malhas da textualidade, em suas construções, e pelo manejo estilístico que o escritor faça dos recursos disponibilizados pelo sistema linguístico. $\mathrm{O}$ escritor mais criativo, mais inquieto, certamente recrutará recursos menos usuais ou mesmo dará feição nova aos recursos já existentes. Assim é que estruturas sintáticas, usos semânticos e lexicais vão-se moldando pela mão do artista para revelar o novo, o surpreendente, o expressivo, o inusitado. O poeta Manoel de Barros declara: "Não gosto de palavra acostumada" (BARROS, 1997). O poeta desacomoda a palavra e a palavra incomoda o leitor. Não entendemos aqui esse incômodo como algo negativo, mas como a provocação necessária para desacostumar, também, o leitor, convidando-o a ultrapassar o portal dos usos cotidianos e adentrar, de fato, o espaço da arte literária, onde ele também pode ser um brincante da linguagem. Quanto menos acomodado o artista, mais incomodado o leitor - e mais forte o chamado para que este transite pelas possibilidades da língua com desenvoltura, de modo a perceber e fruir realmente o texto. Assim, quanto maior o repertório linguístico do leitor e quanto maior sua desenvoltura no trato do sistema da língua, maiores suas possibilidades de leitura e, consequentemente, de fruição. O texto pode, de fato, ser opaco para o leitor desavisado - mas se dá ao que tem olhos de ver. 
Nesse ponto, temos uma questão à qual, vez por outra, voltam-se as discussões, seja na sociedade como um todo, seja nas escolas e academias: a possível opacidade da linguagem de alguns autores pode obstaculizar a leitura e, sobretudo, o prazer da leitura? Em vista disso, seria interessante produzir uma simplificação desses textos, de modo a torná-los mais acessíveis ao leitor menos afeito a sofisticações linguísticas? Tais questões polarizam posicionamentos e, até, afrontam educadores, mas não se pode deixar de reconhecer que têm guarida em alguns meios. Foi a partir desse questionamento sobre leitura que se conduziu, em sala de aula, uma prática voltada para a estilística.

Passamos a relatar um percurso de discussões e de prática pedagógica em sala de ensino médio, envolvendo o manejo estilístico dos escritores em geral e, mais especificamente, de Machado de Assis, João Ubaldo Ribeiro e Mia Couto. A sala de aula é de turma da 3ạ. série do ensino médio do Colégio Pedro II (escola pública federal voltada para a educação básica, no Rio de Janeiro), campus Tijuca II. Nessa escola, Literatura e Língua não são conteúdos separados cabe ao professor de Português construir abordagens que coloquem sempre em diálogo as construções linguísticas e os percursos literários. 


\section{A PROPOSTA}

As atividades descritas compuseram uma sequência didática e desenvolveram-se num total de 6 tempos-aula (cada tempo com 45 minutos), assim distribuídos: 2 tempos para leitura de texto de João Ubaldo sobre o tema, seguida de debate e de pontuações do professor, com recuperação de conteúdo linguístico (conceituação de ironia, polifonia textual, polissemia, metáfora e metonímia); 2 tempos para atividade a partir de texto de Mia Couto; 2 tempos para produção de texto dissertativo-argumentativo sobre o tema. A atividade com o texto de Mia Couto serviu a dois propósitos: o de verificação do que se havia tematizado anteriormente e o de coleta de dados para pesquisa de uma orientanda da especialização em Língua Portuguesa da Uerj, que, em sua monografia, aborda o trato dos alunos com os neologismos (RITTER, 2016).

\section{ENCONTRO}

Partimos de uma crônica de João Ubaldo Ribeiro, intitulada "Reescrevendo a História". Contextualizou-se para os alunos a motivação do texto (recuperando, nesse ponto, a característica do gênero textual crônica de fundar-se no cotidiano). Nesse texto, o cronista trata do debate, em curso na sociedade, no ano de 2014 , a respeito de se produzirem 
simplificações do texto machadiano, sob a alegação de que o original seria de leitura extremamente difícil para o leitor escolar. Com objetivo alegado de favorecer o acesso à leitura, produziu-se versão simplificada do texto "O alienista", que o MEC iria distribuir. É o que diz a autora da versão, Patrícia Secco, explicando a motivação e os objetivos do projeto:

A ideia do projeto não é facilitar os textos, mas facilitar o acesso à leitura. Fiz uma transposição da linguagem da época para a linguagem atual. Fiquei muito chateada com as reações, porque o projeto só visa levar Machado a quem não conhece. Não é fazer com que ele deixe de ser Machado, fazer grandes modificações. É para que o leitor não fique parado ou derrapando. (GLOBO NEWS, 2014, s/p.)

Com base nessa polêmica, João Ubaldo escreve a supracitada crônica, em que, por meio de ironias e contraditórios, critica o projeto e defende a inexistência de separação entre forma e conteúdo, na literatura:

A observação inicial que se pode fazer sobre tal premissa é que ela se fundamenta na crença, comum entre pessoas semiletradas e analfabetos funcionais, de que, na obra literária, existe uma diferença, ou separação, entre forma e conteúdo. O conteúdo seria a "história", o "enredo". A forma seriam as palavras usadas pelo escritor e seu jeito de narrar. (RIBEIRO, 2014, s/p.) 
No primeiro momento após a leitura da crônica, antes de se abrir francamente o debate sobre o tema, fez-se breve enquete sobre como se posicionavam os estudantes quanto ao que foi lido/informado: $50 \%$ da turma discordaram de que o texto literário devesse ser modificado; 25\% aceitariam modificações sutis de vocabulário, como forma de tornar o texto acessível a leitores que não têm uma educação de qualidade e, consequentemente, não teriam como "decifrar" o texto de Machado de Assis; 25\% aceitariam plenamente a criação de versões simplificadas, embora admitindo a perda estilística, mas entendendo que a simplificação resultaria na inclusão de leitores, até que tivessem estatura para ler o original. Em nenhum momento, a leitura da obra original foi desvalorizada e se verificou, entre os que apoiaram a simplificação, uma preocupação com a democratização da leitura ("crianças não entenderiam Machado de Assis, se não fosse simplificado"; "quem não tem uma escola de qualidade não pode chegar a compreender Machado" etc.).

Em seguida, no trabalho com o texto propriamente dito, os alunos foram chamados a: 1) identificar o posicionamento do cronista quanto ao tema; 2) analisar estratégia de argumentação e argumentos em si; 3) posicionarem-se quanto ao que foi lido. Dessa etapa, resultou a percepção 
de que Ubaldo, para ser compreendido adequadamente em seu posicionamento, demanda um leitor atento, capaz de identificar ironias e contraditórios. Viu-se que, na realidade, o cronista parte de um argumento que será, ao longo da crônica, desconstruído e até ridicularizado. Os alunos reconheceram que Ubaldo maneja estratégias linguísticas e argumentativas para defender sua tese, que só é explicitada quase ao final do texto. Até lá, as adjetivações e nomeações (como na citação anterior, ao usar os vocábulos crença, semiletradas, analfabetos funcionais para referir-se ao projeto em discussão e aos que o apoiam) vão oferecendo ao leitor pistas do posicionamento do autor e construindo a possibilidade de ler a ironia presente em trechos como:

Ou seja, o problema é com Machado, cujos textos obsoletos são preservados supersticiosamente e já não têm serventia para as gerações presentes. Urge, portanto, que nos livremos dessa tralha inútil e elitista, corrigindo o muito que clama por atualização. (RIBEIRO, $2014, \mathrm{~s} / \mathrm{p}$.).

Ficou claro para os estudantes que o reconhecimento da ironia reclama um leitor preparado, assim como os textos de Machado. Foi realizada, então, a leitura de um fragmento do conto "Missa do galo", de Machado de Assis, seguida de perguntas sobre como os alunos receberam/ 
perceberam o texto. De modo geral, a opinião foi de que apenas o vocabulário ocasionalmente representava desafio, muitas vezes solucionado pelo contexto. $\mathrm{O}$ estilo, as figuras, os processos enfáticos e metafóricos usados pelo autor no fragmento foram acompanhados com facilidade pelos alunos.

Numa nova etapa, os estudantes foram confrontados com as seguintes perguntas, cuja pretensão era fazer refletir sobre o posicionamento originalmente expresso, logo após a leitura da crônica de João Ubaldo Ribeiro: a) Se Machado de Assis não é tipicamente um escritor para crianças, por que simplificar o seu texto? b) $\mathrm{O}$ que é mais produtivo para a sociedade: simplificar o texto ou preparar o leitor? A discussão que se seguiu a essas perguntas, com novos posicionamentos dos estudantes, resultou em uma mudança na estatística do debate: $80 \%$ passaram a rejeitar a simplificação, apoiando a apresentação do texto machadiano, conforme a realidade cognitiva dos leitores; $20 \%$ continuaram a defender a simplificação como estratégia democratizante e temporária, a dar lugar à obra original, que deveria ser apresentada ao leitor quando ele pudesse lê-la adequadamente. Encerrado o debate, pediu-se aos alunos que registrassem livremente em seus cadernos as suas reflexões sobre o tema (esse material serviria de base para a produção textual, a ser proposta, ao final da sequência). 


\section{ENCONTRO}

No encontro seguinte, realizou-se leitura de fragmento do romance Terra sonâmbula, de Mia Couto. O fragmento foi selecionado com um objetivo específico: verificar como os alunos processam um texto com muitas ocorrências neológicas, investigando que estratégias são usadas por eles para tal processamento. Paralelamente, colocavam-se outros objetivos: verificar como reagem os leitores ao estilo do autor, apurar se identificam os recursos linguísticos usados por ele para produzir a ambiência textual e conduzir o fio da narrativa. Os resultados relativos aos neologismos estarão publicados em trabalho monográfico de RITTER (no prelo) e não serão adiantadas aqui, mas, quanto ao modo pelo qual os alunos percebem o estilo, pudemos observar que, em sua avaliação, o uso de neologismos e de construções pouco convencionais, do ponto de vista sintático, constituíram uma provocação percebida como positiva pelos alunos. Eles declararam que, mesmo tropeçando em alguns vocábulos (usamos intencionalmente o termo 'tropeçando', para dialogar com a declaração de Patrícia Secco quanto a seu projeto de simplificação), puderam ler o todo e, até, sentiramse estimulados a usar a criatividade, tendo sido projetados num mundo de imaginação - o mundo da ficção miacoutiana. 
Instados a produzir fragmentos com os neologismos vistos no texto, de acordo com seu entendimento, os alunos demonstraram certa sensação de divertimento no manejo linguístico - estavam diante da palavra-brinquedo, a palavra séria de fato, como nos diz Manoel de Barros, em epígrafe.

\section{3ㅇ ENCONTRO}

Por se tratar de turma de 3a série do ensino médio, que tem no exame do Enem um desafio a superar, a produção de texto focalizou-se no modelo dissertativo-argumentativo, retomando-se as anotações feitas após o debate. Após lerem, discutirem e vivenciarem o lugar do leitor diante do desconhecido ou do texto-provocação, estavam os alunos mais preparados para discutirem, do ponto de vista ideológico, a admissibilidade ou não do projeto de simplificação de obras literárias.

\section{CONSIDERAÇÕES FINAIS}

Estilo é identidade. É também identificação - do leitor com a obra, com o autor, com a língua, com a cultura. Confirmando o que diz Ubaldo (2014), não se pode promover o "aviltamento de marcos essenciais ao autorrespeito cultural e à identidade da nação", pela desfiguração de obras literárias emblemáticas. Deve-se preparar o leitor, afastando a miopia decorrente de um vocabulário afunilado e de parcas leituras. 
As atividades desenvolvidas demonstraram que a abordagem estilística tem lugar na sala de aula - mas deve ser (e aqui nos posicionamos) realizada sempre a partir do texto e em diálogo constante com ele, não a partir de listas de figuras e recursos, que restam inertes diante da realidade. Olhar para o vocabulário com curiosidade brincante, descobrir no texto os sentidos ocultos, divertir-se com os (des)caminhos do texto - tudo isso é a estilística como parte da atividade escolar. Melhor, ainda, se o aluno se estimular a brincar a sério com a palavra poética, descobrindo em si um escritor.

Uma palavra final - para todo esse trabalho, há que se ter docentes preparados, familiarizados com a Estilística, donde o seu estudo se coloca como fundamental. Ao professor, as teorias precisam chegar; as nomenclaturas e definições devem ser conhecidas - não para que as use obrigatoriamente com seus alunos do ensino básico, mas para que, enxergando longe, oriente-os com segurança.

\section{REFERÊNCIAS}

BARROS, Manoel de. (1997). Livro sobre nada. Rio de Janeiro: Record. CÂMARA JR., Joaquim Mattoso (1978). Contribuição à estilística portuguesa. 3.ed. Rio de Janeiro: Ed. Ao Livro Técnico.

DISCINI, Norma (2009). O estilo nos textos: história em quadrinhos, mídia, literatura. 2.ed. São Paulo: Contexto.

GLOBO NEWS. "Versão simplificada de livro de Machado de Assis gera polêmica". Disponível em http://g1.globo.com/globo-news/ 
noticia/2014/05/versao-simplificada-de-livro-de-machado-de-assisgera-polemica.html. Acesso em 17.mai.2014.

GUIRAUD, Pierre (1970). A Estilística. São Paulo: Mestre Jou.

LAPA, Manuel R. (1998). Estilística da Língua Portuguesa. Rio de Janeiro: Martins Fontes.

MARTINS, Nilce Sant'Anna (2000). Introdução à estilística: a expressividade na língua portuguesa. São Paulo: T. A. Queiroz.

MONTEIRO, José Lemos (2005). A estilística: manual de análise e criação do estilo literário. Petrópolis: Ed. Vozes.

POSSENTI, Sírio (2001). Discurso, estilo e subjetividade. 2.ed., São Paulo: Martins Fontes.

REI, Cláudio Artur O. (2002). A Palavra Caetana: estudos estilísticos. Rio de Janeiro: UERJ (Dissertação de Mestrado).

RIBEIRO, João Ubaldo (2014). "Reescrevendo a História". Crônica. In: Jornal O Globo, Opinião. Disponível em http://oglobo.globo.com/opiniao/ reescrevendo-historia-12671527. Acesso em 01.jun.2014.

RITTER, Celita Aparecida Damasceno (2016). A reinvenção do signo na leitura de estudantes do ensino médio a partir de neologismos da obra "Terra sonâmbula" de Mia Couto sob uma abordagem semântica e estilística. Monografia. Orientadora: Profa. Dra. Lúcia Deborah Ramos de Araujo. Especialização em Língua Portuguesa - Programa de PósGraduação em Letras - UERJ.

Fabio André Cardoso Coelho é doutor em Língua Portuguesa. Professor de Língua Portuguesa e Filologia, do Instituto de Letras da UERJ. Atua na Graduação em Letras e na Pós-Graduação em Língua Portuguesa. Autor de diversos artigos e livros, também organizados, dentre eles "Ensino de Produção Textual", pela Editora Contexto. Professor pesquisador do Grupo de Pesquisa Descrição e Ensino de Língua: Pressupostos e Práticas (CNPq).

Lúcia Deborah Ramos de Araujo é doutora em Língua Portuguesa. Professora Adjunta de Língua Portuguesa do Instituto de Letras da UERJ 
e Professora do Colégio Pedro II. Atua na Graduação em Letras e na Pós-Graduação em Língua Portuguesa (na UERJ) e no Ensino Médio do Colégio Pedro II. Membro do Grupo de Pesquisa SELEPROT - Semiótica, Leitura e Produção de Textos (CNPq).

Recebido em 10 de julho 2016. Aprovado em 28 de outubro de 2016. 